\title{
In short supply
}

\section{Geographer Robert McDonald gathered a team of hydrologists, freshwater ecologists, urban planners} and demographers to estimate the impacts of urban growth and climate change on future water availability for major cities in the developing world.

\begin{abstract}
What was the impetus for this project and what was the main objective of the work at the beginning of the project? The predicted huge wave of urbanization was the key motivator for this work, as water scarcity is going to be an even bigger challenge for cities in the developing world in the future than it is at present. Furthermore, in some developing regions, climate change as well as demographic trends will also pose challenges to the distribution of water because of its expected impacts on the global hydrologic cycle and on precipitation patterns. For this project, we focused on water availability only, and we left aside the issues around water delivery and
\end{abstract}

ANALYSIS WORLD HELPED GATHERED MARKET $)$ RESEARCH

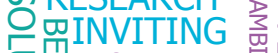
员 PROBLEM

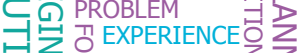
O'zO

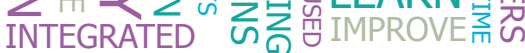
PROPOSE OBJECTIVES BACKGROUNDS URBANIZATION

OUTCOMES 齐 SHORTAGE

11 O NEEDED MECHANISMS

ת DREATION FUTURE HYDROLOGY

CHALLENGE AGREEMENT DIFFICULTIES

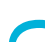

만

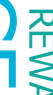

$\sum \square$
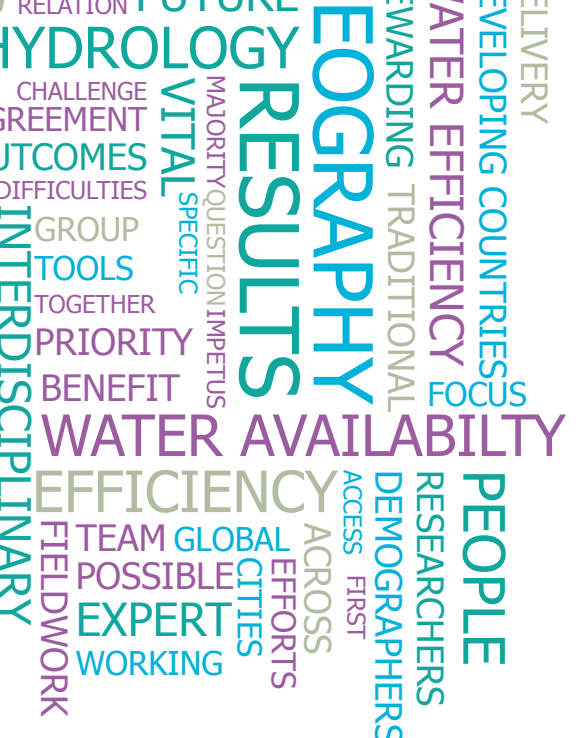

quality, as analysing access to water at a global level is a quite challenging research effort itself. Our particular focus in this paper was on identifying developing world cities most at risk of water shortage, and then trying to propose possible solutions for those cities.

\section{How did you go about finding suitable collaborators?}

We tried to be careful in pulling the team together. We definitely wanted to have known people on board as that simplifies the whole process. We opted for inviting reputed researchers who were willing to devote enough time to the project and at the same time who had an open mind so that they would fit well in an interdisciplinary team. We ended up with a large interdisciplinary group.

\section{Did any difficulties arise in working} with a team of experts with different research backgrounds and perspectives? In my view there were two main difficulties. First, everyone tended to be too committed to their own fieldwork to free time for the project. In other words, the project was not a priority for the majority of the researchers involved. Second, the ambition of this project was to go beyond traditional ecology to achieve an integrated view of the problem of water shortage in developing world cities. It was difficult though to get to a common definition of the problem across members of the team as we were all speaking different languages and looking at the problem from very different perspectives. A lot of conversations took place initially. Having a proposal with a clear key question at hand ultimately helped to keep the group together and to avoid a loss of focus in developing the work.

What was the highlight of working with an interdisciplinary team? Working with colleagues from other disciplines was great fun! At the beginning there was the challenge of finding agreement as a group on the key research questions, but the experience was rewarding in the end. You can learn a lot by interacting with people from different research backgrounds as each expert looks at the issue from a different angle, and clearly specialists end up asking particular research questions, very much grounded on their specific discipline.

\section{Did you learn any lessons about} interdisciplinary collaboration from this project that would benefit others trying to do similar work?

First, I would say that it is vital to be interdisciplinary from the beginning. Setting the project together makes it easier to develop the research work as the key questions are defined and agreed by the group from the start. Second, it is very important to not be afraid of producing concise analyses within an interdisciplinary group. There is often a tendency to set very ambitious research goals when a large interdisciplinary team is going to do the job. In the majority of cases, though, massive research efforts end up without achieving the expected results or generally lead to unsatisfactory outcomes.

\section{Any final thoughts?}

Our paper represents a start at analysing how climate change affects water distribution across cities, but I think that more scientific work is needed to understand the problem thoroughly and to be able to propose solutions. After that, more research is needed on water inefficiencies, in particular in relation to the agricultural sector in terms of more efficient irrigation strategies, and to urbanization in terms of more adequate infrastructure for the distribution of water to residents. These issues are traditionally treated as market failures, but ultimately we need to understand them more to support and better inform the design of policy mechanisms to improve efficiency.

\section{INTERVIEW BY}

\section{MONICA CONTESTABILE}

This Beyond Boundaries is based on the work by Robert McDonald and colleagues, published in Proc. Natl Acad. Sci. USA doi: 10.1073/pnas.1011615108 (2011). 